\title{
Effects of Hawthorn on the Progression of Heart Failure in a Rat Model of Aortic Constriction
}

\author{
Hyun Seok Hwang, M.S., Marvin O. Boluyt, Ph.D., Kimber Converso, B.S., \\ Mark W. Russell, M.D., and Barry E. Bleske, Pharm.D., FCCP
}

Study Objective. To determine the effects of hawthorn (Crataegus oxycantha) on left ventricular remodeling and function in pressure overload-induced heart failure in an animal model.

Design. Randomized, parallel, dose-ranging animal study.

Setting. University research facility.

Animals. Seventy-four male Sprague-Dawley rats; 44 were included in the final analysis.

Intervention. Rats underwent a sham operation or aortic constriction. Rats subjected to the sham operation were treated with vehicle (10\% agar-agar), and those subjected to aortic constriction were treated with vehicle or hawthorn (C. oxycantha special extract WS 1442) 1.3, 13, or $130 \mathrm{mg} / \mathrm{kg}$ for 5 months.

Measurements and Main Results. Rats and their hearts were weighed, and echocardiographic measurements were performed at baseline and at 2, 3, 4, and 5 months after aortic constriction. Protein expression for markers of fibrosis and for atrial natriuretic factor was also measured. Aortic constriction increased the left ventricular:body weight ratio by $53 \%$ in vehicle-treated rats; Hawthorn treatment did not significantly affect the aortic constriction-induced increase in this ratio. Left ventricular volumes and dimensions at systole and diastole significantly increased 5 months after aortic constriction compared with baseline in rats given vehicle ( $>20 \%$ increase, $\mathrm{p}<0.05)$ but not in those given hawthorn $130 \mathrm{mg} / \mathrm{kg}(<10 \%$ increase). After aortic constriction, the velocity of circumferential shortening significantly decreased in the vehicle group but not in the medium- or high-dose groups. In the aortic constriction-vehicle group, the induced increases in messenger RNA expression for atrial natriuretic factor $(\sim 1000 \%)$ and fibronectin $(\sim 80 \%)$ were significantly attenuated by highdose hawthorn treatment by approximately $80 \%$ and $50 \%$, respectively.

Conclusion. Hawthorn treatment exhibited modest beneficial effects on cardiac remodeling and function during long-term, pressure overloadinduced heart failure in rats.

Key Words: hawthorn, Crataegus oxycantha, heart failure, atrial natriuretic factor, ANF, left ventricular volume, fibronectin, animal study.

(Pharmacotherapy 2009;29(6):639-648)

Heart failure is a clinical syndrome with diverse causes and has progressive cardiac dysfunction as its distinguishing characteristic. ${ }^{1}$ All patients with systolic heart failure have left ventricular dysfunction, but cardiac dysfunction itself does not always lead to symptoms of the disease. Left ventricular remodeling plays an important role in the progression of chronic heart failure. Early remodeling is an adaptive response to the increased load on the heart and/or the loss 
of contractile components to maintain pumping capacity. However, prolonged overload taxes the limits of adaptive mechanisms, forcing compromises that result in progressive deterioration of pump function. Ultimately, the left ventricle enlarges, and its diastolic and/or systolic function is impaired.

Aortic constriction in rats causes chronic left ventricular pressure overload, progressive cardiac remodeling, and subsequent cardiac failure that mimics heart failure in humans. ${ }^{2-4}$ Pressure overload also induces an increase in cardiac fibrosis, resulting in diastolic dysfunction, again similar to findings in humans., ${ }^{5,}$ In addition, this rat model leads to initial compensatory hypertrophy that progresses to heart failure in a predictable manner akin to the progression seen in people. Finally, effects of angiotensinconverting enzyme (ACE) inhibitors (and other drugs) in this model are similar to those observed in human heart failure. ${ }^{4}$ Overall, chronic aortic constriction-induced pressure overload is a good model to study the effects of drugs on the development and progression of heart failure.

At present, an estimated $38 \%$ of the adult population of the United States uses herbal therapy. ${ }^{7}$ Hawthorn (Crataegus oxycantha) is a popular botanical treatment for heart disease, including heart failure, especially in Europe and China. Early trials demonstrated that hawthorn may offer modest beneficial effects in the treatment of heart failure. ${ }^{8,9}$ Recent trials, however, have not shown an especially striking benefit for heart failure that is well treated with standard drug therapy. ${ }^{10,11}$

We recently demonstrated that short-term hawthorn treatment improved cardiac functions in pressure overload-induced cardiac remodeling. ${ }^{12}$ However, whether long-term treatment with

From the Division of Kinesiology, Laboratory of Molecular Kinesiology, University of Michigan, Ann Arbor Michigan (Mr. Hwang and Dr. Boluyt); the Division of Pediatric Cardiology, Department of Pediatrics and Communicable Diseases, University of Michigan Health Systems, Ann Arbor, Michigan (Ms. Converso and Dr. Russell); and the Department of Clinical and Social Administrative Sciences, College of Pharmacy, University of Michigan, Ann Arbor, Michigan (Dr. Bleske).

Supported by National Institutes of Health, National Center for Complementary and Alternative Medicine R21 Award (AT002192-01).

Manuscript received August 28, 2008. Accepted pending revisions October 10, 2008. Accepted for publication in final form November 6, 2008.

Address reprint requests to Barry E. Bleske, Pharm.D., FCCP, College of Pharmacy, University of Michigan, 428 Church Street, Ann Arbor, MI 48109-1065; e-mail: bbleske@umich.edu. hawthorn influences the progression of heart failure-specifically cardiac remodeling and fibrosis-is unknown. Therefore, the purpose of this study was to determine the effects of hawthorn on the progression of heart failure in a rat model of chronic pressure overload.

\section{Methods}

Animals

Male Sprague-Dawley rats, each weighing 250-275 g, were obtained from Charles River Laboratories (Wilmington, MA). The rats were housed two or three to a cage, fed a standard laboratory diet (5001; PMI Nutrition International, Richmond, IN), given water ad libitum, and maintained on a cycle of 12 hours light and 12 hours dark. The University Committee on Use and Care of Animals at the University of Michigan approved all animal protocols, which conformed to the Guiding Principles in the Care and Use of Animals of the American Physiological Society.

\section{Experimental Design}

The rats were subjected to a sham operation or aortic constriction. Rats subjected to the sham operation were treated with vehicle (10\% agaragar), and those subjected to aortic constriction were treated with vehicle or three doses of hawthorn (C. oxycantha special extract WS 1442; Dr. Willmar Schwabe Pharmaceuticals GmbH \& Co. KG, Karlsruhe, Germany) for 5 months beginning 1 week after aortic constriction.

Crataegus oxycantha special extract WS 1442 is a dry extract derived from hawthorn leaves with flowers, with a raw material:extract ratio of 4-6.6:1 using 45\% (weight/weight) ethanol as extraction solvent. The extract is adjusted to contain 17.3-20.1\% oligomeric procyanidins. The batch we used (Ch. 289 N001) contained $18.8 \%$ oligomeric procyanidins, $2.9 \%$ flavonoids (calculated as hyperoside), $0.4 \%$ oleanolic acid, and $1 \%$ cyanidin (calculated as cyanidin chloride).

The doses and administration schedule for hawthorn were similar to those previously described. ${ }^{12}$ In brief, the recommended dosage of hawthorn in humans is $900 \mathrm{mg} /$ day. This is approximately $13 \mathrm{mg} / \mathrm{kg} /$ day for a $70-\mathrm{kg}$ person. As a result, we selected a human dose of 13 $\mathrm{mg} / \mathrm{kg}$ as our middle dose and used doses 10-fold higher and 10-fold lower to achieve a reasonable dose-response range. Therefore, doses were 1.3 
(low), 13 (medium), or 130 (high) mg/kg. Hawthorn was administered by oral gavage at approximately 5:00 P.M.

After 1 week of aortic constriction, the initial treatment groups consisted of the following: sham operation-vehicle group (12 rats), aortic constriction-vehicle group (15), aortic constriction-low-dose group (17), aortic constrictionmedium-dose group (15), and aortic constriction-high-dose group (15). We terminated the study when the mortality rate reached approximately $50 \%$ in any of the treated aorticconstriction groups. Therefore, the study ended at 5 months. The decision to terminate the trial at a $50 \%$ mortality rate was made to ensure that we had adequate power at the end of the study and that a transition to decompensated heart failure could occur. Before the study ended, we conducted a final echocardiographic assessment. Afterward, we euthanized the rats and excised and dissected their hearts to collect the right ventricle, septum, left ventricular free wall, left atrium, and right atrium. Tissues were stored at $80^{\circ} \mathrm{C}$ for subsequent isolation of RNA and protein.

\section{Aortic Constriction}

Aortic constriction was conducted as described previously. $^{2}$ In brief, we performed left thoracotomy with the animal under anesthesia induced with pentobarbital $50 \mathrm{mg} / \mathrm{kg}$ and exposed the ascending aorta. A Weck hemoclip was placed around the ascending aorta $4-6 \mathrm{~mm}$ superior to the aortic valve, with the gap of the Weck hemoclip applicator set at $1.02 \mathrm{~mm}$.

\section{Outcome Measures}

We assessed body and ventricular weights, mortality rates, relative wall thickness, and cardiac function (left ventricular dimension in systole and diastole, stroke volume, velocity of circumferential shortening, and fractional shortening). In addition, we examined the expression of messenger RNA (mRNA) for atrial natriuretic factor (ANF), $\beta$-myosin heavy chain, and fibronectin, as well as the abundance of collagen type III.

\section{Echocardiography}

We echocardiographically measured cardiac function at baseline ( 1 wk before aortic constriction) and at 2, 3, 4, and 5 months after aortic constriction. ${ }^{13}$ Two-dimensional, guided,
M-mode recordings were obtained from the short-axis view at the level of the papillary muscles by using a system (Acuson Sequoia; Siemens Medical Solutions, Malvern, PA) equipped with a $15-\mathrm{MHz}$ linear-array transducer or a system (Vivid 7; GE Medical Systems, Milwaukee, WI) equipped with a $10-\mathrm{MHz}$ phased-array transducer (S10-MHz; GE Medical Systems).

For each M-mode measurement, at least three consecutive cardiac cycles were sampled, as previously described. ${ }^{13}$ A single echocardiographer performed all measurements in accordance with the conventions of the American Society of Echocardiography.

Relative wall thickness was defined as 2 times the thickness of the posterior wall in diastole divided by the dimension of the left ventricle during diastole. Relative wall thickness was used instead of absolute wall thickness to facilitate comparisons among rats because of inherent variances from rat to rat.

\section{RNA Blotting}

Blotting for RNA was performed as described previously, with modifications. ${ }^{2,14}$ We isolated RNA from the left ventricle and size-fractionated $10 \mu \mathrm{g}$ of total RNA by electrophoresis through $1 \%$ agarose gels. Samples were transferred electrophoretically at $5 \mathrm{~V} / \mathrm{cm}$ to a nylon membrane (Nytran SPC; Whatman Inc., Piscataway, NJ) and hybridized with ${ }^{32} \mathrm{P}$-radiolabeled probes overnight at $68^{\circ} \mathrm{C}$ for complementary DNA probes and at $42-45^{\circ} \mathrm{C}$ for oligonucleotide probes by using a hybridization buffer (PerfectHyb Plus; Sigma-Aldrich Corp., St. Louis, MO).

Hybridization intensity was quantified with a Personal Phosphorimager FX (Bio-Rad Laboratories, Hercules, CA). Signals visualized on computer screen were identified by their position relative to migration of $18 \mathrm{~S}$ and $28 \mathrm{~S}$ ribosomal RNA. They were delineated by rectangles and quantified after subtracting the background. Each blot was subsequently stripped and reprobed. The signal from each sample was normalized to the signal obtained with an oligonucleotide specific for the $3^{\prime}$ untranslated region of glyceraldehyde-3' phosphate dehydrogenase. The probe for $\beta$ myosin heavy chain was an oligonucleotide described previously. ${ }^{14}$ Complementary DNA probes for ANF and fibronectin were synthesized from a template by the random prime method (Promega Corp., Madison, WI). 
Table 1. Postmortem Analysis During 5 Months of Pressure Overload by Treatment Group ${ }^{\mathrm{a}}$

\begin{tabular}{|c|c|c|c|c|c|c|}
\hline \multirow[b]{2}{*}{ Variable } & \multirow[b]{2}{*}{$\begin{array}{l}\text { Sham Operation, } \\
\text { Vehicle Group } \\
(\mathrm{n}=12)\end{array}$} & \multicolumn{4}{|c|}{ Aortic Constriction } & \multirow[b]{2}{*}{$\mathrm{p}$ Value } \\
\hline & & $\begin{array}{l}\text { Vehicle Group } \\
\qquad(n=9)\end{array}$ & $\begin{array}{l}\text { Hawthorn } \\
\text { Low-Dose } \\
\text { Group } \\
(n=10)\end{array}$ & $\begin{array}{c}\text { Hawthorn } \\
\text { Medium-Dose } \\
\text { Group } \\
(\mathrm{n}=6)\end{array}$ & $\begin{array}{c}\text { Hawthorn } \\
\text { High-Dose } \\
\text { Group } \\
(\mathrm{n}=7)\end{array}$ & \\
\hline \multirow[t]{2}{*}{ Mortality rate ${ }^{a}$} & $0 \%$ & $40 \%(6 / 15)$ & $41 \%(7 / 17)$ & $60 \%(9 / 15)$ & $53 \%(8 / 15)$ & $<0.05^{b}$ \\
\hline & & & Mean \pm SEM & & & \\
\hline Initial body weight (g) & $262 \pm 6.6$ & $261 \pm 8.5$ & $253 \pm 6$ & $278 \pm 8.9$ & $269 \pm 6.1$ & $<0.01^{\mathrm{c}}$ \\
\hline Final body weight (g) & $561 \pm 22$ & $555 \pm 22$ & $554 \pm 13$ & $542 \pm 35$ & $536 \pm 17$ & $<0.01^{\mathrm{c}}$ \\
\hline $\begin{array}{l}\text { LV dry:LV wet ratio } \\
\text { (mg:mg) }\end{array}$ & $0.23 \pm 0.003$ & $0.23 \pm 0.002$ & $0.22 \pm 0.003$ & $0.22 \pm 0.005$ & $0.22 \pm 0.004$ & $\geq 0.05$ \\
\hline $\begin{array}{l}\text { RV:body weight ratio } \\
\text { (mg:g) }\end{array}$ & $0.51 \pm 0.02$ & $0.53 \pm 0.02$ & $0.62 \pm 0.05$ & $0.53 \pm 0.03$ & $0.55 \pm 0.02$ & $\geq 0.05$ \\
\hline
\end{tabular}

SEM = standard error of the mean; LV = left ventricular; RV = right ventricular.

${ }^{a}$ End-point variables were evaluated by using 1-way analysis of variance followed by the least significant difference post hoc procedure. Mortality was determined by Kaplan-Meier analysis.

${ }^{b}$ For all aortic-constriction groups vs sham operation-vehicle group.

${ }^{c}$ For all comparisons over the course of the experiment.

\section{Immunoblotting for Collagen Type III}

Portions of the frozen left ventricle were processed for immunoblotting, as described elsewhere. ${ }^{2}$ Relative levels of collagen type III were measured protein using a monoclonal antibody directed at collagen type III (Santa Cruz Biotechnology, Santa Cruz, CA). Signals were quantified by using enhanced chemiluminescence.

\section{Statistical Analysis}

Data are expressed as percentages or mean \pm standard error of the mean. Mortality rates were determined by Kaplan-Meier analysis. End-point variables were analyzed by using a l-way analysis of variance (ANOVA), and group differences were determined with the least significant difference post hoc procedure. Contrasts were performed to compare the aortic constriction-vehicle group with the three hawthorn dose groups combined to determine the overall effect of hawthorn.

Echocardiographic data were analyzed by using 2-way ANOVA (group $\mathrm{x}$ time) with repeated measures, and group differences were determined with the least significant difference post hoc procedure. When the interaction for group $\mathrm{x}$ time was significant, a l-way ANOVA procedure with repeated measures was conducted for each group separately, followed by the least significant difference post hoc procedure to determine differences between time points within a group. Differences were considered statistically significant when $\alpha$ was 0.05 or less.

\section{Results}

Forty-four rats survived to the end of the study
(5 mo): sham operation-vehicle group (12 rats), aortic constriction-vehicle group (9), aortic constriction-low-dose group (10), aortic

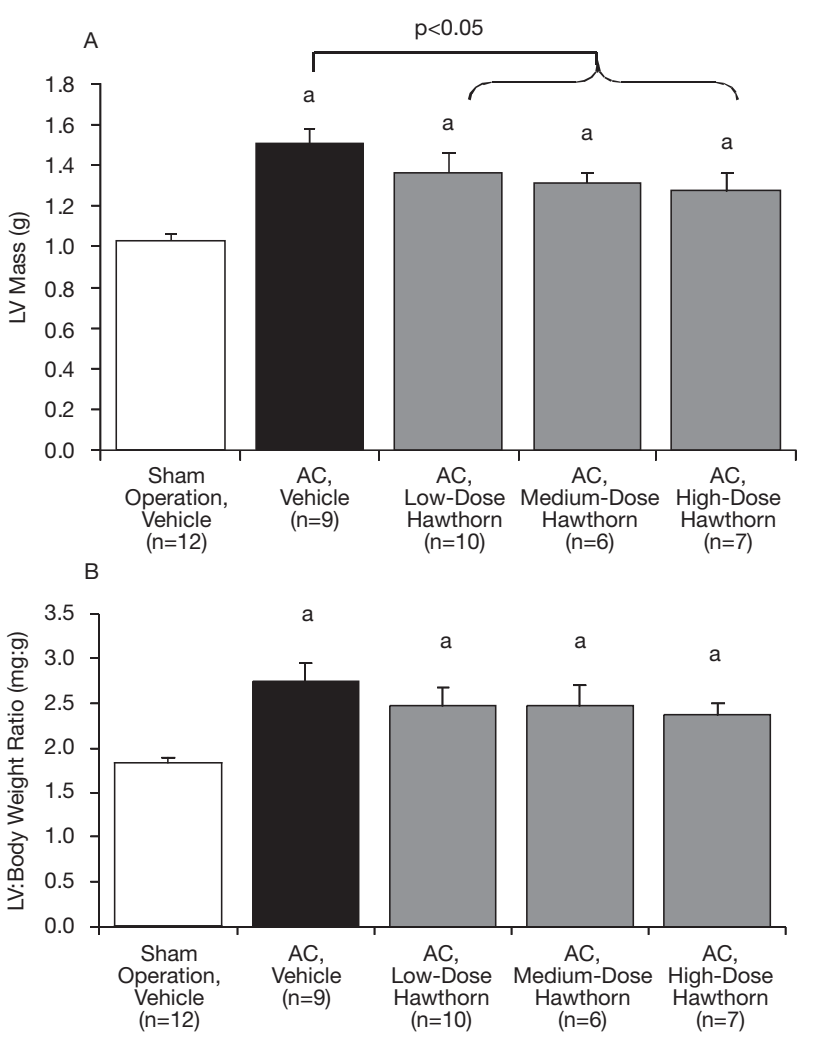

Figure 1. Cardiac hypertrophy after 5 months of pressure overload assessed as left ventricular (LV) mass (panel A) and the LV:body weight ratio (panel B) at the end point of the experiment. Data are mean \pm standard error of the mean. $\mathrm{AC}=$ aortic constriction. ${ }^{\mathrm{a}} \mathrm{p}<0.05$ vs sham operation-vehicle group (1-way analysis of variance followed by the least significant difference post hoc procedure). 
Table 2. Structural and Functional Cardiac Adaptations in Response to Chronic Pressure Overload and Hawthorn Treatment

\begin{tabular}{|c|c|c|c|c|c|}
\hline \multirow[b]{2}{*}{ Measure $^{a}$} & \multirow[b]{2}{*}{$\begin{array}{l}\text { Sham Operation, } \\
\text { Vehicle Group } \\
(\mathrm{n}=12)\end{array}$} & \multicolumn{4}{|c|}{ Aortic Constriction } \\
\hline & & $\begin{array}{l}\text { Vehicle Group } \\
\qquad(\mathrm{n}=9)\end{array}$ & $\begin{array}{l}\text { Hawthorn } \\
\text { Low-Dose } \\
\text { Group } \\
(\mathrm{n}=10)\end{array}$ & $\begin{array}{c}\text { Hawthorn } \\
\text { Medium-Dose } \\
\text { Group } \\
(\mathrm{n}=6)\end{array}$ & $\begin{array}{c}\text { Hawthorn } \\
\text { High-Dose } \\
\text { Group } \\
(\mathrm{n}=7)\end{array}$ \\
\hline \multicolumn{6}{|l|}{$\begin{array}{l}\text { Stroke volume } \\
\text { (ml/beat) }\end{array}$} \\
\hline Baseline & $205 \pm 19.4$ & $197 \pm 19.9$ & $190 \pm 17.7$ & $192 \pm 16.7$ & $228 \pm 26.0$ \\
\hline Month 2 & $359 \pm 25.4^{b}$ & $297 \pm 40.2^{b}$ & $303 \pm 34.2^{b}$ & $245 \pm 33.5$ & $282 \pm 40.8$ \\
\hline Month 3 & $371 \pm 19.7^{\mathrm{b}}$ & $388 \pm 49.7^{\mathrm{b}}$ & $382 \pm 20.6^{\mathrm{b}}$ & $303 \pm 25.3^{b}$ & $306 \pm 40.0$ \\
\hline Month 4 & $429 \pm 27.7^{b}$ & $296 \pm 35.4^{b, c}$ & $361 \pm 34.5^{\mathrm{b}}$ & $289 \pm 34.7^{b, c}$ & $335 \pm 31.7^{c}$ \\
\hline Month 5 & $418 \pm 24.0^{\mathrm{b}}$ & $319 \pm 17.4^{b, c}$ & $413 \pm 36.1^{\mathrm{b}}$ & $344 \pm 32.2^{\mathrm{b}}$ & $319 \pm 52.5^{c}$ \\
\hline Percent change $^{\mathrm{d}}$ & +103 & +62 & +117 & +79 & +40 \\
\hline \multicolumn{6}{|l|}{$\begin{array}{l}\text { LV dimension, } \\
\text { diastole }(\mathrm{mm})\end{array}$} \\
\hline Baseline & $6.29 \pm 0.23$ & $6.20 \pm 0.20$ & $6.05 \pm 0.21$ & $6.25 \pm 0.18$ & $6.59 \pm 0.21$ \\
\hline Month 2 & $7.78 \pm 0.21^{\mathrm{b}}$ & $7.30 \pm 0.34^{b}$ & $7.25 \pm 0.38^{\mathrm{b}}$ & $6.70 \pm 0.37$ & $6.99 \pm 0.31$ \\
\hline Month 3 & $7.81 \pm 0.16^{\mathrm{b}}$ & $7.84 \pm 0.34^{b}$ & $7.87 \pm 0.21^{\mathrm{b}}$ & $7.07 \pm 0.20^{\mathrm{b}}$ & $7.20 \pm 0.45$ \\
\hline Month 4 & $8.15 \pm 0.20^{\mathrm{b}}$ & $7.30 \pm 0.33^{b}$ & $7.81 \pm 0.32^{\mathrm{b}}$ & $7.05 \pm 0.28^{b}$ & $7.44 \pm 0.28$ \\
\hline Month 5 & $8.26 \pm 0.19^{b}$ & $7.58 \pm 0.20^{\mathrm{b}}$ & $8.20 \pm 0.28^{b}$ & $7.72 \pm 0.30^{\mathrm{b}}$ & $7.20 \pm 0.38$ \\
\hline Percent change $^{\mathrm{d}}$ & +31 & +22 & +37 & +24 & +9 \\
\hline \multicolumn{6}{|l|}{$\begin{array}{l}\text { LV dimension, } \\
\text { systole }(\mathrm{mm})\end{array}$} \\
\hline Baseline & $3.71 \pm 0.17$ & $3.60 \pm 0.13$ & $3.25 \pm 0.24$ & $3.77 \pm 0.17$ & $3.94 \pm 0.17$ \\
\hline Month 2 & $4.88 \pm 0.21^{b}$ & $4.59 \pm 0.37^{b}$ & $4.33 \pm 0.44^{b}$ & $3.83 \pm 0.45$ & $4.06 \pm 0.26$ \\
\hline Month 3 & $4.73 \pm 0.19^{b}$ & $4.73 \pm .034^{\mathrm{b}}$ & $4.59 \pm 0.36^{b}$ & $3.72 \pm 0.23$ & $4.07 \pm 0.57$ \\
\hline Month 4 & $4.85 \pm 0.24^{b}$ & $4.54 \pm 0.41^{b}$ & $4.78 \pm 0.45^{b}$ & $3.95 \pm 0.36$ & $4.31 \pm 0.30$ \\
\hline Month 5 & $5.28 \pm 0.21^{\mathrm{b}}$ & $4.84 \pm 0.29^{b}$ & $5.13 \pm 0.37^{b}$ & $4.65 \pm 0.58$ & $4.07 \pm 0.28$ \\
\hline Percent change $^{\mathrm{d}}$ & +42 & +34 & +58 & +23 & +3 \\
\hline \multicolumn{6}{|l|}{$\begin{array}{l}\text { Fractional } \\
\text { shortening (\%) }\end{array}$} \\
\hline Baseline & $40.8 \pm 1.7$ & $41.8 \pm 0.3$ & $47.1 \pm 2.5$ & $39.7 \pm 2.3$ & $40.0 \pm 2.3$ \\
\hline Month 2 & $37.5 \pm 1.5$ & $37.5 \pm 3.3$ & $41.2 \pm 3.1$ & $43.3 \pm 4.1$ & $41.9 \pm 3.3$ \\
\hline Month 3 & $39.6 \pm 1.6$ & $40.1 \pm 2.9$ & $42.1 \pm 3.3$ & $47.5 \pm 2.6$ & $44.6 \pm 4.8$ \\
\hline Month 4 & $40.7 \pm 2.0$ & $38.5 \pm 3.7$ & $39.6 \pm 3.9$ & $44.0 \pm 4.3$ & $42.3 \pm 2.1$ \\
\hline Month 5 & $36.3 \pm 1.4$ & $36.7 \pm 2.4$ & $37.7 \pm 2.8$ & $40.3 \pm 5.4$ & $43.3 \pm 2.6$ \\
\hline Percent change $^{\mathrm{d}}$ & -9 & -12 & -20 & +2 & +8 \\
\hline $\begin{array}{l}\text { Data are mean } \pm \text { stanc } \\
\text { Baseline }=1 \text { wk befor } \\
\text { a For all measures, } 2 \\
\text { following p values: g } \\
{ }^{\mathrm{b}} \mathrm{p}<0.05 \text { compared wi } \\
{ }^{\mathrm{c}} \mathrm{p}<0.05 \text { compared wit } \\
\mathrm{d} \text { Calculated as (value }\end{array}$ & $\begin{array}{l}\text { error of the mean. } \\
\text { tic constriction. } \\
\text { analysis of varian } \\
\mathrm{p} \geq 0.05 \text {, time } \mathrm{p}<0.0 \\
\text { aseline value within } \\
\text { tam operation-vehic } \\
\text { months - baseline v }\end{array}$ & $\begin{array}{l}\text { group } x \text { time } p \\
\text { reatment group } \\
\text { e at same time } \\
\text { aseline value. }\end{array}$ & & post $\mathrm{h}$ & are yielded \\
\hline
\end{tabular}

constriction-medium-dose group (6), and aortic constriction-high-dose group (7). Increases in body weight from before the operation to 5 months after the operation were similar in the sham operation-vehicle group and aortic constriction group-vehicle group. This result indicated that neither hawthorn treatment nor aortic constriction influenced the increase in body weight that occurred over the course of the experiment (Table 1).

After 5 months, left ventricular mass was 47\% greater in the aortic-constriction groups than in the sham operation-vehicle group $(\mathrm{p}<0.05$;
Figure 1A). Hawthorn treatment significantly attenuated the increase in left ventricular mass caused by aortic constriction. Aortic constriction increased the left ventricular:body weight ratio by $53 \%$ in vehicle-treated rats $(p<0.001)$. The influence of hawthorn on the aortic constrictioninduced increase in this ratio was not statistically significant, although the trend was similar to changes observed for left ventricular mass alone (Figure 1B).

During 5 months of aortic constriction-induced pressure overload, the mortality rate was $40 \%$ for vehicle-treated rats. No significant differences 
were seen when these rats were compared with hawthorn-treated rats (Table 1). Aortic constriction significantly increased relative wall thickness by $40 \%$ in vehicle-treated rats. Over time, lowand medium-dose hawthorn treatment significantly diminished the increase in constrictioninduced relative wall thickness (Figure 2).

Left ventricular dimension in systole and diastole significantly increased by greater than $20 \%$ over baseline in the aortic constriction-vehicle group; however, no significant increase (<10\%) was observed in the aortic constriction-highdose group (Table 2). Likewise, left ventricular volumes at end of systole and end of diastole did not significantly increase at 5 months after aortic constriction in the aortic constriction-high-dose group. Significant increases were observed in the aortic constriction-vehicle group (Figure 3A and 3B). In aggregate, the data indicated that highdose hawthorn modified aortic constrictioninduced cardiac remodeling most significantly.

Aortic constriction attenuated the increase in stroke volume that occurred over time in vehicletreated rats (Table 2). Constriction-induced attenuation of the increase in stroke volume over time was counteracted, especially by low and medium doses of hawthorn. Velocity of circumferential shortening significantly decreased in the aortic constriction groups treated with vehicle or low-dose hawthorn. However, medium and high

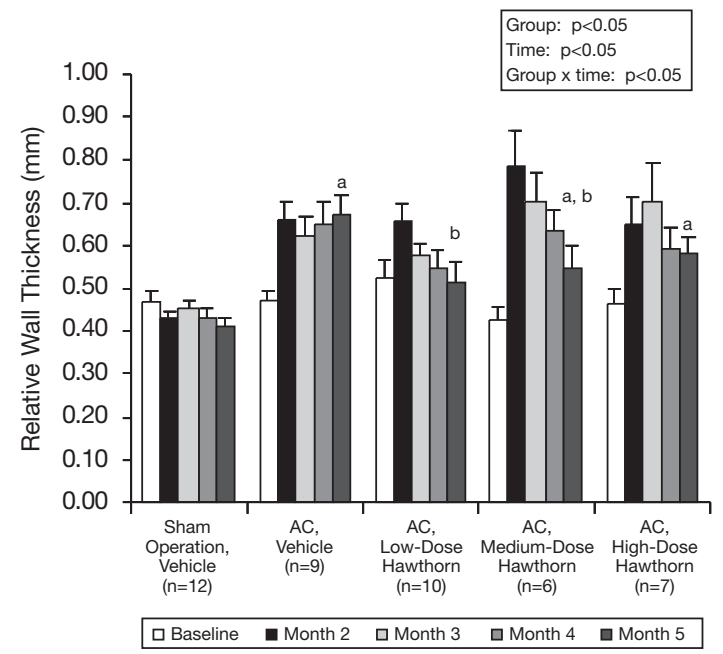

Figure 2. Cardiac remodeling, assessed as relative wall thickness, during 5 months of pressure overload. Data are mean \pm standard error of the mean. Data were analyzed by using a 2-way analysis of variance with repeated measures followed by the least significant difference post hoc procedure. $\mathrm{AC}=$ aortic constriction; baseline $=1$ week before AC. ${ }^{\mathrm{a}} \mathrm{p}<0.05$ vs sham operation-vehicle group at 5 months; ${ }^{\mathrm{b}} \mathrm{p}<0.05$ vs aortic constriction-vehicle group at 5 months. doses did not significantly lower velocity of circumferential shortening after 5 months of aortic constriction (Figure 3C).
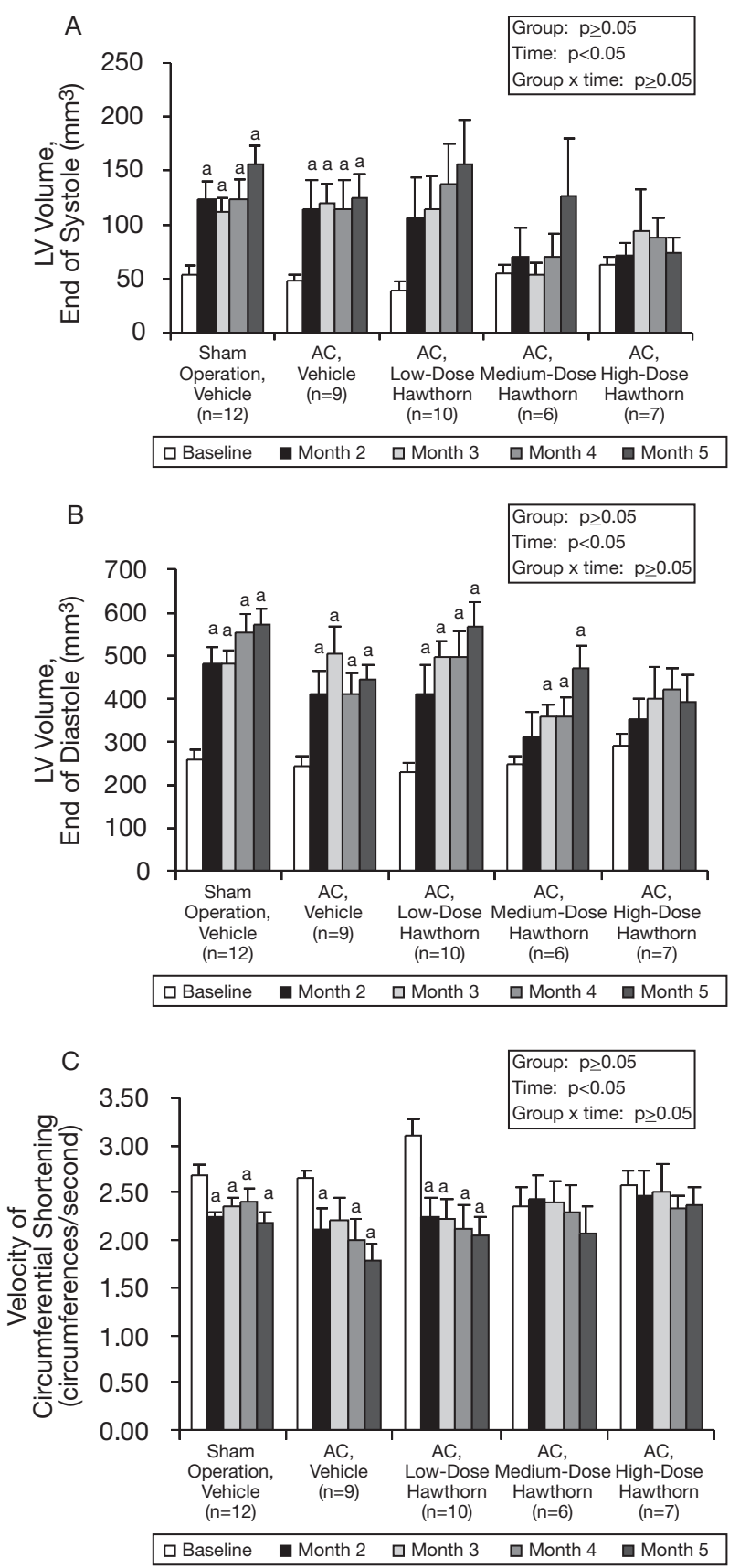

Figure 3. Cardiac function during 5 months of pressure overload evaluated as left ventricular volume (LV) at end of systole (panel A), left ventricular volume at end of diastole (panel B), and velocity of circumferential shortening in the left ventricle (panel C). Data are mean \pm standard error of the mean. Data were analyzed by using a 2-way analysis of variance with repeated measures followed by the least significant difference post hoc procedure. $\mathrm{AC}=$ aortic constriction; baseline $=1$ week before AC. ${ }^{a} \mathrm{p}<0.05$ vs baseline within the same treatment group. 
For the sham operation-vehicle, aortic constriction-vehicle, and aortic constrictionlow-dose groups, fractional shortening was lower at 5 months compared with baseline (Table 2). In contrast, fractional shortening seemed to improve in the medium- and high-dose groups. Overall, the data suggested that hawthorn given at a high dose maintained cardiac function better than vehicle after 5 months of aortic constriction.

At 5 months, levels of ANF mRNA significantly rose by $1000 \%$ in the hearts of rats who received aortic constriction and vehicle (Figure 4A). Each dose of hawthorn almost completely counteracted the increase in ANF mRNA caused by long-term
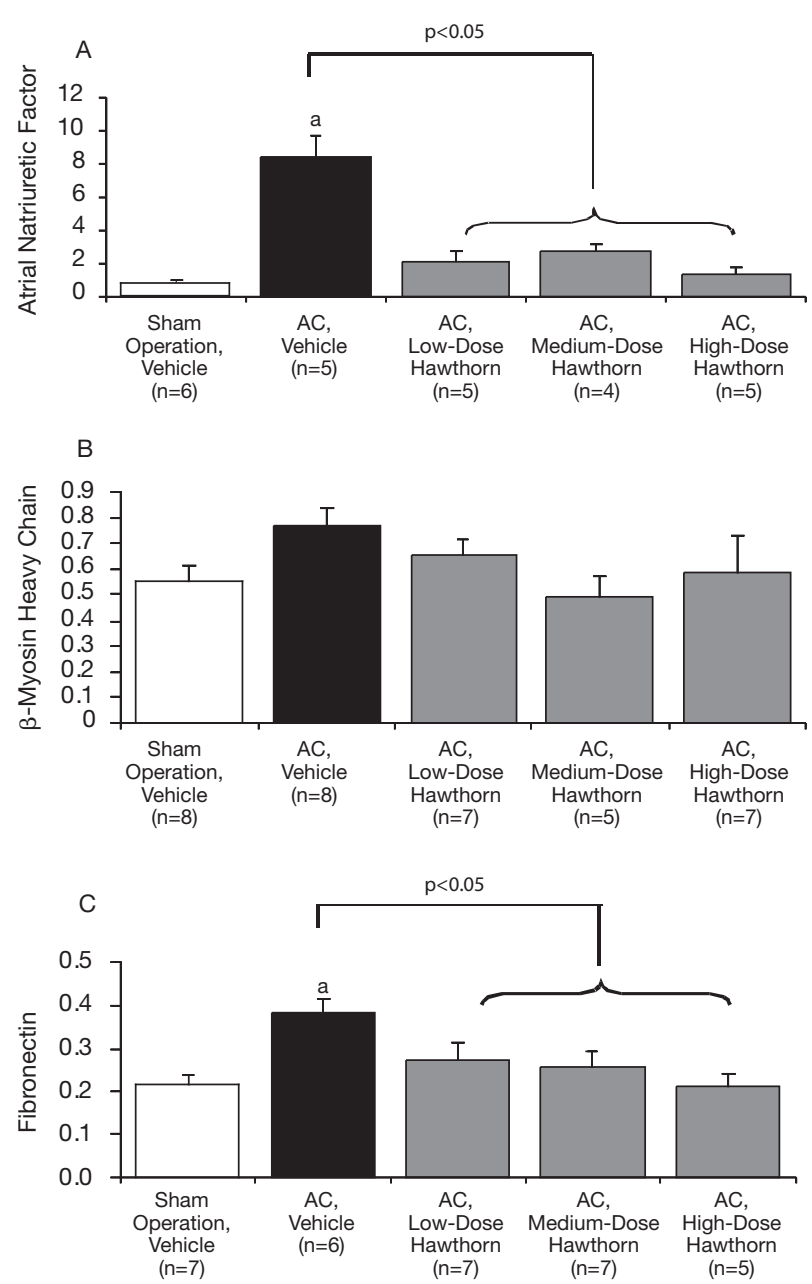

Figure 4. Expression of hypertrophy-associated messenger RNA in the left ventricle for atrial natriuretic factor (panel A), $\beta$-myosin heavy chain (panel B), and fibronectin (panel C). Data are mean \pm standard error of the mean. $A C=$ aortic constriction. Brackets indicate contrasts for the AC-vehicle group vs the AC-low-dose, AC-medium-dose, and AC-highdose groups combined. ${ }^{a} \mathrm{p}<0.05$ vs sham operation-vehicle group (1-way analysis of variance followed by the least significant difference post hoc procedure). aortic constriction. At 5 months after sham operation or aortic constriction, levels of mRNA for $\beta$-myosin heavy chain did not significantly differ among any of the five groups (Figure 4B). After pressure overload, expression of fibronectin mRNA in the left ventricle significantly increased by $78 \%$ (Figure 4C). Each of the three doses of hawthorn markedly attenuated the aortic constriction-induced increase in mRNA expression for fibronectin.

The abundance of collagen type III protein was significantly and similarly elevated in the three aortic constriction groups treated with vehicle or medium or high doses of hawthorn compared with the sham operation-vehicle group (Figure 5). Collagen type III protein levels in the aortic constriction-low-dose group were not significantly greater than those of the sham-vehicle group, but they were also not significantly lower than the aortic constriction-vehicle levels. Taken together, these data showed that hawthorn treatment had little, if any, effect on the aortic constriction-induced increase in the abundance of collagen III protein.

\section{Discussion}

Our survival data indicate that our model of pressure overload likely caused a progression of heart failure, which increased mortality rates in rats undergoing aortic constriction compared with those receiving sham operation plus vehicle. The most potent effects of hawthorn were observed for variables that reflected the nature of cardiac remodeling. These included marked suppression of the aortic constriction-induced

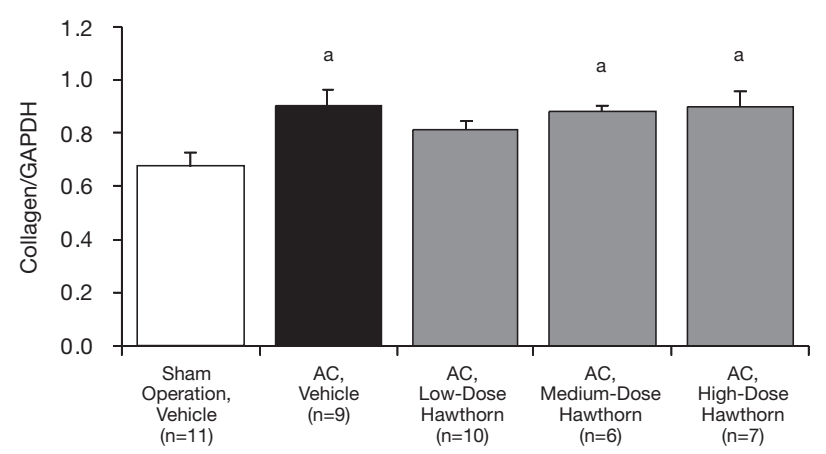

Figure 5. Abundance of collagen type III protein in the left ventricle after 5 months. Levels were measured by immunoblotting and normalized to the signal for glyceraldehyde-3'-phosphate dehydrogenase (GAPDH). Data are mean \pm standard error of the mean. $A C=$ aortic constriction. ${ }^{\mathrm{a}} \mathrm{p}<0.05$ vs sham operation-vehicle group (1way analysis of variance followed by the least significant difference post hoc procedure). 
increase in mRNA expression for ANF and fibronectin, as well as alterations in structural remodeling. All doses of hawthorn positively influenced ANF and fibronectin mRNA expression. At the highest dose, hawthorn favorably affected ventricular size and systolic function. The results suggest that hawthorn exerted important effects on remodeling and on the progression of heart failure in a pressure overload model of heart failure.

To our knowledge, this was the first study to show that hawthorn treatment influences cardiac remodeling in the context of long-term pressure overload. Hawthorn attenuated the increase in left ventricular mass after aortic constriction. Although the left ventricular:body weight ratio was not significantly attenuated, the trend was similar to that observed with left ventricular mass. Given other findings for remodeling parameters, although the trend is not statistically significant, it is likely to be clinically significant. The mean percentage increase in left ventricular systolic and diastolic dimensions was less than $10 \%$ ( $p>0.05$ vs baseline) in the high-dose hawthorn group after 5 months of aortic constriction compared with an increase of greater than $20 \%(p<0.05$ vs baseline $)$ in the aortic constriction-vehicle group. We noted similar findings regarding left ventricular systolic and diastolic volumes. In support of these results, ANF expression, which increases in response to pressure and stretch, was significantly lower in the hawthorn groups than in the aortic constriction-vehicle group.

Possible mechanisms for the benefits of hawthorn on cardiac remodeling are likely multifactorial given its wide range of reported effects on the myocardium and on signaling pathways. These include inotropic actions on cardiac muscle that may indirectly benefit remodeling of the heart, as well as a vasodilatory property of hawthorn that may be attributed to nitric oxide. ${ }^{15,16}$ Another factor to consider is that hawthorn exhibited protective effects against ischemia-reperfusion injury by conferring mitochondrial protection. ${ }^{17,18}$ If true, prevention of mitochondrial damage and apoptosis would be consistent with improved remodeling because it would prevent loss of myocytes that can lead to weakening and fibrosis.

Additional mechanisms-or mechanisms that may explain the observed effects of hawthornmay also be proposed on the basis of observed effects of the agent or its individual constituents (flavonoids and polyphenolic compounds).
These additional mechanisms may include effects on reactive oxygen species, nitric oxide (endothelial and inducible nitric oxide synthases), and specific signaling pathways involving p38 mitogenactivated protein kinase, nuclear factor- $\mathrm{B}$, and extracellular signal-regulated kinases 1 and $2{ }^{19-26}$

The intrinsic ability of the ventricles to contract was maintained most with the medium and high doses of hawthorn after aortic constriction, as evidenced by the lack of change in the velocity of circumferential shortening and fractional shortening. By comparison, these parameters decreased in the vehicle and low-dose groups after aortic constriction. These findings were consistent with our observations regarding ventricular remodeling in this study. Together, the data suggest that hawthorn may attenuate the transition from compensated to decompensated heart failure after long-term pressure overload. The apparent effects of hawthorn to lessen a maladaptive form of hypertrophy that we found were consistent with our previous results from a short-term model of pressure overload. ${ }^{12}$ In that model, hawthorn maintained a more adaptive form of hypertrophy after aortic constriction than vehicle, on the basis of the velocity of circumferential shortening and relative wall thickness.

Potential mechanisms to account for the effects on systolic function include beneficial effects on apoptosis, reactive oxygen species, endothelial nitric oxide synthase, and inducible nitric oxide synthase, along with inotropic actions of hawthorn. Previous studies have shown that hawthorn increases the inotropic activity of cardiac muscle. ${ }^{15}$ Moreover, treatment of failing human myocardium with hawthorn increases both the calcium iontransient and the force production of papillary muscles from these hearts. The mechanism of these inotropic effects is partly attributed to the ability of hawthorn to inhibit $\mathrm{Na}^{+}-\mathrm{K}^{+}$-adenosine $5^{\prime}$-triphosphatase. ${ }^{15}$

Many studies have shown that ANF mRNA levels increase in response to a wide range of hypertrophic stimuli, including aging, long-term $\beta$-adrenergic stimulation, aortic constriction, thyroid hormone, hypertension, exercise training, and coronary artery occlusion. ${ }^{27,28}$ Therefore, repeat induction of gene expression for ANF in the left ventricle is one of the most reliable markers of cardiac hypertrophy. Levels of ANF mRNA were significantly elevated in spontaneously hypertensive rats compared with normotensive Wistar-Kyoto rats and increased even further when hypertension-induced hypertrophy progressed to heart failure. ${ }^{14}$ In the 
present study, hawthorn almost completely abolished the increase in ANF mRNA levels caused by 5 months of pressure overload. These data helped confirm our findings that hawthorn significantly affects ventricular remodeling.

Excessive accumulation of proteins of the extracellular matrix, fibronectin, and collagen causes myocardial fibrosis that results in stiffening of the heart and diastolic dysfunction. ${ }^{29}$ Type III collagen is one of the two major types of collagen expressed in the heart. Type III collagen accounts for approximately $20 \%$ of the total collagen in rat heart tissue. Levels of mRNA for collagen type III are transiently elevated in the heart after aortic constriction in chronic hypertension and during the transition from compensated hypertrophy to heart failure. ${ }^{2,5,14}$ Fibronectin is a large protein of the extracellular matrix that binds together various components and cells of the matrix, contributing to its overall integrity. Fibronectin gene expression increases in response to advancing age, aortic constriction, chronic hyper-

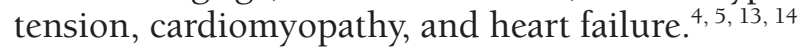

In our study, 5 months of aortic constriction increased levels of type III collagen by $35 \%$ and increased fibronectin mRNA levels by $78 \%$, consistent with previous findings., 2, 6 Hawthorn treatment did not significantly attenuate the aortic constriction-induced increase in type III collagen protein. Hawthorn did, however, attenuate the constriction-induced increase in fibronectin mRNA expression, suggesting that it may have modified the nature of extracellular matrix to some extent. The lack of effect on the abundance of collagen type III protein suggests that hawthorn did not mitigate the aortic constriction-induced increase in the total amount of extracellular matrix. Effects of hawthorn on fibronectin expression may contribute, at least in part, to modest changes in end-diastolic dimension and volume, as we observed in some of the hawthorn-treated groups.

One obvious limitation was that this investigation was an animal study and that mechanisms for the results found were not well defined. However, ANF was suppressed in the hawthorntreated groups, and this finding appears to confirm our results regarding structural remodeling. Another limitation was that this was not a mortality trial; therefore, inferences from our mortality results are limited. Although mortality rates seemed to be higher in the hawthorn groups than in the others, we found no clear dose response, and these findings were likely the result of chance. Given the few animals studied, one death can dramatically alter interpretation of the data.

Also of note, echocardiography was performed at five time points, and data for rats that died before the 5-month end point were excluded from the final analysis. When we examined the last echocardiographic measurements obtained from rats that died before this point, we noted no obvious indications of heart failure (e.g., marked reduction in fractional shortening or left ventricular ejection fraction). Autopsies were not conducted for rats that died before the endpoint analysis. Therefore, although heart failure due to pressure overload was the assumed cause of death, no autopsy or echocardiographic data were available to confirm this assumption.

From a clinical perspective, a potential limitation of this study was the fact that hawthorn was not administered with standard-of-care therapies such as ACE inhibitors and $\beta$-blockers. On the other hand, this design might actually have been the strength of the study in that hawthorn could demonstrate its effects on the progression of heart failure. One can easily reason that powerful remodeling drugs such as ACE inhibitors and $\beta$ blockers may mask or attenuate the effects of hawthorn on remodeling. In clinical terms, this may have important therapeutic implications, particularly in patients who cannot tolerate or who are not candidates for standard-of-care ACE inhibition or $\beta$-blockade. Because hawthorn has shown remodeling effects similar to those of both these treatments, high-risk patients who cannot receive this standard of care are most likely to benefit from hawthorn therapy, especially with regard to ventricular remodeling. Perhaps an important niche for complementary and alternative medicine may be the treatment of patients who cannot tolerate or who are not candidates for standard approaches.

\section{Conclusion}

Our data suggest that hawthorn attenuates maladaptive ventricular remodeling and decreases in systolic function associated with longstanding pressure overload. Of note, these findings are consistent with the observation that hawthorn attenuates increases in ANF, a marker related to cardiac hypertrophy, and in fibronectin, a marker associated with fibrosis. Our study demonstrated the importance of herbal therapy in a rat model of heart failure. Further studies in humans are now warranted to determine the effect of hawthorn on ventricular remodeling. 


\section{Acknowledgments}

The authors thank Aaron LaRock, Rhett Butler, Michael M. J. Ghannam, and Agdas Mikkor for their assistance. Also, a special thank you to Dr. Willmar Schwabe Pharmaceuticals GmbH \& Co. KG, Karlsruhe, Germany, for supplying Crataegus special extract WS 1442 for the study.

\section{References}

1. Jessup M, Brozena S. Heart failure. N Engl J Med 2003;348:2007-18.

2. Cirrincione GM, Boluyt MO, Hwang HS, Bleske BE. 3-HMGcoenzyme A reductase inhibition and extracellular matrix gene expression in the pressure-overloaded rat heart. J Cardiovasc Pharmacol 2006;47:521-30.

3. Boluyt MO, Opiteck JA, Esser KA, White TP. Cardiac adaptations to aortic constriction in adult and aged rats. Am J Physiol 1989;257:H643-8.

4. Weinberg EO, Schoen FJ, George D, et al. Angiotensinconverting enzyme inhibition prolongs survival and modifies the transition to heart failure in rats with pressure overload hypertrophy due to ascending aortic stenosis. Circulation 1994;90:1410-22.

5. Villarreal FJ, Dillmann WH. Cardiac hypertrophy-induced changes in mRNA levels for TGF-beta 1, fibronectin, and collagen. Am J Physiol 1992;262:H1861-6.

6. Kuwahara F, Kai H, Tokuda K, et al. Transforming growth factor-beta function blocking prevents myocardial fibrosis and diastolic dysfunction in pressure-overloaded rats. Circulation 2002;106:130-5.

7. National Center for Complementary and Alternative Medicine, National Institutes of Health. The use of complementary and alternative medicine in the United States. Available from http://nccam.nih.gov/news/camstats/2007/ camsurvey_fsl.htm. Accessed March 20, 2009.

8. Pittler MH, Schmidt K, Ernst E. Hawthorn extract for treating chronic heart failure: meta-analysis of randomized trials. Am J Med 2003;114:665-74.

9. Tauchert M. Efficacy and safety of crataegus extract WS 1442 in comparison with placebo in patients with chronic stable New York Heart Association class-III heart failure. Am Heart J 2002;143:910-15.

10. Aaronson K. HERB-CHF (hawthorn extract randomized blinded chronic HF study): late-breaking and recent clinical trials. Presented at the 8 th annual scientific meeting of the Heart Failure Society of America, Toronto, Ontario, Canada, September 12-15, 2004.

11. Holubarsch CJ, Colucci WS, Meinertz T, Gaus W, Tendera M, for the Survival and Prognosis: Investigation of Crataegus Extract WS 1442 in CHF (SPICE) Trial Study Group. The efficacy and safety of Crataegus extract WS 1442 in patients with heart failure: the SPICE trial. Eur J Heart Fail 2008; 10:1255-63.

12. Hwang HS, Bleske BE, Ghannam MJ, et al. Effects of hawthorn on cardiac remodeling and left ventricular dysfunction after 1 month of pressure overload-induced cardiac hypertrophy in rats. Cardiovasc Drugs Ther 2008;22:19-28.

13. Boluyt MO, Converso K, Hwang HS, Mikkor A, Russell MW. Echocardiographic assessment of age-associated changes in systolic and diastolic function of the female F344 rat heart. J
Appl Physiol 2004a;96:822-8.

14. Boluyt MO, O'Neill L, Meredith AL, et al. Alterations in cardiac gene expression during the transition from stable hypertrophy to heart failure: marked upregulation of genes encoding extracellular matrix. Circ Res 1994;75:23-32.

15. Schwinger RH, Pietsch M, Frank K, Brixius K. Crataegus special extract WS 1442 increases force of contraction in human myocardium cAMP-independently. J Cardiovasc Pharmacol 2000;35:700-7.

16. Chen ZY, Zhang ZS, Kwan KY, Zhu M, Ho WK, Huang Y. Endothelium-dependent relaxation induced by hawthorn extract in rat mesenteric artery. Life Sci 1998;63:1983-91.

17. Veveris M, Koch E, Chatterjee SS. Crataegus special extract WS 1442 improves cardiac function and reduces infarct size in a rat model of prolonged coronary ischemia and reperfusion. Life Sci 2004;74:1945-55.

18. Jayalakshmi R, Thirupurasundari CJ, Devaraj SN. Pretreatment with alcoholic extract of Crataegus oxycantha (AEC) activates mitochondrial protection during isoproterenolinduced myocardial infarction in rats. Mol Cell Biochem 2006;292:59-67.

19. Bahorun T, Trotin F, Pommery J, Vasseur J, Pinkas M Antioxidant activities of Crataegus monogyna extracts. Planta Med 1994;60:323-8.

20. Bahourn T, Aumjaud E, Ramphul H, et al. Phenolic constituents and antioxidant capacities of Crataegus monogyna (hawthorn) callus extracts. Food 2003;47:191-8.

21. Zhang Z, Chang Q, Zhu M, Huang Y, Ho WKK, Chen ZY. Characterization of antioxidants present in hawthorn fruits. J Nutr Biochem 2001;12:144-52.

22. Wang L, Tu YC, Lian TW, Hung JT, Yen JH, Wu MJ. Distinctive antioxidant and anti-inflammatory effects of flavonols. J Agric Food Chem 2006;54:9798-804.

23. Sanchez M, Galisteo M, Vera R, et al. Quercetin downregulates NADPH oxidase, increases eNOS activity and prevents endothelial dysfunction in spontaneously hypertensive rats. J Hypertens 2006;24:75-84.

24. Kim SH, Kang KW, Kim KW, Kim ND. Procyanidins in crataegus extract evoke endothelium-dependent vasorelaxation in rat aorta. Life Sci 2000;67:121-31.

25. Garcia-Mediavilla V, Crespo I, Collado PS, et al. The antiinflammatory flavones quercetin and kaempferol cause inhibition of inducible nitric oxide synthase, cyclooxygenase-2 and reactive $\mathrm{C}$-protein, and down-regulation of the nuclear factor kappaB pathway in Chang liver cells. Eur J Pharmacol 2007;557:221-9.

26. Oak MH, Chataigneau M, Keravis T, et al. Red wine polyphenolic compounds inhibit vascular endothelial growth factor expression in vascular smooth muscle cells by preventing the activation of the p38 mitogen-activated protein kinase pathway. Arterioscler Thromb Vasc Biol 2003;23:1001-7.

27. Younes A, Boluyt MO, O'Neill L, Meredith AL, Crow MT, Lakatta EG. Age-associated increase in rat ventricular ANP gene expression correlates with cardiac hypertrophy. Am J Physiol 1995;269:H1003-8.

28. Boluyt MO, Cirrincione GM, Loyd AM, Korzick DH, Parker JL, Laughlin MH. Effects of gradual coronary artery occlusion and exercise training on gene expression in swine heart. Mol Cell Biochem 2007;294:87-96.

29. Weber KT, Brilla CG, Janicki JS, Reddy HK, Campbell SE. Myocardial fibrosis: role of ventricular systolic pressure, arterial hypertension, and circulating hormones. Basic Res Cardiol 1991;86(suppl 3):25-31. 